\title{
Conducting Composites of Polypyrrole with Polytetramethylbisphenol A Carbonate
}

\author{
EMRE KALAYCIOGLU, URAL AKBULUT, and LEVENT TOPPARE* \\ Department of Chemistry, Middle East Technical University, 06531 Ankara, Turkey
}

\begin{abstract}
SYNOPSIS
A new conducting composite of polypyrrole (PPy) has been prepared electrochemically where polytetramethylbisphenol A carbonate is used as the insulating matrix polymer. Characterization of the freestanding films of the composites were based on scanning electron microscopy, differential scanning calorimetry, and Fourier transform infrared studies as well as electrical conductivity measurements and solubility. Electrical conductivities were measured by a four-probe technique. Spectroscopic methods, together with conductivity and solubility studies, indicate that the synthesized composite is a homogeneous blend of the two polymers. No evidence of hydrogen bonding in the composite or grafting of the two polymers has been found, contrary to the PPy-polybisphenol A carbonate case. (C) 1996 John Wiley \& Sons, Inc.
\end{abstract}

\section{INTRODUCTION}

In recent years, numerous studies on electrical conducting polymers have been published. This intensive interest may be attributed to possible widespread applications of conducting polymers. Heterocyclic polymers particularly have high conductivity, such as polypyrrole (PPy) and polythiophene (PTh), and their derivatives are of great interest. $^{1-5}$ These heterocyclic polymers are prepared as freestanding films by the electrochemical oxidation of the monomers on platinum or ITO electrodes. ${ }^{6-8}$ However, these conducting polymers have some disadvantages in practical use due to their poor mechanical and physical properties. As reported by several groups, the electrochemical polymerization of the monomer can also occur on an electrode which is already coated with an ordinary insulating polymer, leading to conducting composites. $^{9-13}$ In this case, monomers of conducting element diffuse into the insulating polymer coated on an electrode and start polymeriza-

* To whom correspondence should be addressed. Present address: Department of Chemistry, Bilkent University, 06533 Ankara, Turkey.

Journal of Applied Polymer Science, Vol. 61, 1067-1075 (1996) (C) 1996 John Wiley \& Sons, Inc. tion in the interface between the electrode surface and the host polymer film. The objective here is to obtain homogeneous polymer composites which carry the properties of both conducting and insulating polymers, to a certain extent. This kind of conducting polymer synthesis not only improves the poor mechanical and physical properties of heterocyclic polymers but also retains the conductivity to a desirable value ${ }^{14-17}$ For some of the composites, several spectroscopic techniques revealed that the composites which were electrochemically synthesized have different behaviors than the simple mechanical mixture of the two polymers. Studies previously reported that unlike PTh/polycarbonate (PC), PTh/polystyrene (PS), and PPy/PS composites, PPy/PC composites possessed very different properties from those of a simple mixture of the two polymers. Low percolation thresholds were obtained via chemical interactions between the $\mathrm{PC}$ and PPy. ${ }^{18-20}$ This can be ascribed to a better homogeneity and also to the possible hydrogen bonding and formation of grafting. Fourier transform infrared (FTIR) analysis of PPy/PC blends revealed that the carbonyl band broadened together with the formation of a new band at $1766 \mathrm{~cm}^{-1}$. This new band was interpreted as the $\mathrm{H}$-bonded carbonyl group in the 


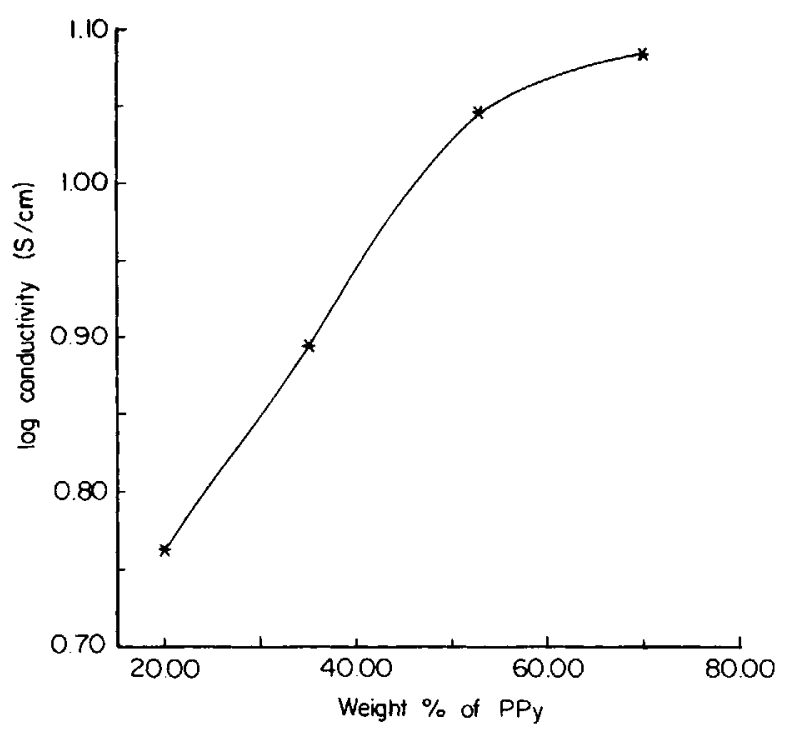

Figure 1 Conductivities of PPy/TMPC films.

composite. In the differential scanning calorimetry (DSC) studies, $\mathrm{PPy} / \mathrm{PC}$ composite gave a specific glass transition temperature $\left(T_{k}\right)$ at $337^{\circ} \mathrm{C}$, whereas the $T_{g}$ of $\mathrm{PC}$ was reported as $145^{\circ} \mathrm{C} .{ }^{21}$ This result reinforced the idea of forming a homogeneous composite of $\mathrm{PPy} / \mathrm{PC}$ not only by simple blending but also by grafting, to a certain extent. Thermogravimetric analysis (TGA) showed that the weight loss did not correspond to the loss of host polymer in the $\mathrm{PPy} / \mathrm{PC}$ composite as it did in some other composites. This observation consequently suggested that the strong chemical bonding formed in the PPy/PC blend was stable enough to prevent the thermal decomposition of pure PC. Scanning electron micrograph (SEM) studies also supported the formation of a homogeneous composite; no morphologic change was observed between SEM photographs of the PPy/ PC films washed with chloroform, the solvent of the host polymer, and the unwashed PPy/PC film.

The earlier report concluded that PPy could approach $\mathrm{PC}$ to create a chemical interaction. We now focus on the synthesis and characterization of homogeneous PPy composites on a polytetramethylbisphenol A carbonate (TMPC)-coated electrode which is prepared by electrochemical technique, as mentioned above. The choice of TMPC lies in the fact that the methyl groups will obscure the formation of $\mathrm{H}$-bonding and grafting due to steric hinderance. We propose that the presence of methyl groups on the insulating polymer will prevent pyrrole oligomers from coming close to the carbonyl moiety of TMPC, thus drastically decreasing the possibility of a chemical interaction between the two polymers. Consequently, the resulting composites will have quite different properties from $\mathrm{PPy} / \mathrm{PC}$ systems.

\section{EXPERIMENTAL}

PPy-TMPC composites were synthesized by electrochemical polymerization of pyrrole onto a TMPCcoated electrode at a constant potential of $+1.5 \mathrm{~V}$ versus $\mathrm{Ag}^{\circ} / \mathrm{Ag}^{+}\left(10^{-2} \mathrm{M}\right)$. A Wenking POS $73 \mathrm{Po}$ tentiostat was used for the supply of a constant potential in the electrochemical polymerization.

TMPC (Bayer) was dissolved in chloroform ( 10 $\mathrm{mg} \mathrm{L}^{-1}$ ) and coated on the platinum electrode by dipping the electrode into the solution. The amounts of insulating and conducting polymer coatings were estimated gravimetrically.

A three-compartment cell equipped with platinum foils $\left(1.5 \mathrm{~cm}^{2}\right)$ as the working and counter electrodes and a capillary reference electrode $\left(\mathrm{Ag}^{\circ} /\right.$ $\mathrm{Ag}^{+}$) was utilized in potentiostatic polymerization. The solvent was acetonitrile (Merck) and the supporting electrolyte was tetrabutylammonium tetrafluoroborate (Aldrich). As a control, the above experiment was also run under the absence of pyrrole. This assured that there were no changes either chemically or by weight in the host polymer. Further details on the potentiostatic electrolyses have been given elsewhere. ${ }^{22}$

Table I Conductivities of Unwashed and Washed Electrolytic Films

\begin{tabular}{ccc}
\hline $\begin{array}{c}\text { Composition of } \\
\begin{array}{c}\text { Electrolytic Films } \\
\text { (in PPy) }\end{array}\end{array}$ & $\begin{array}{c}\text { Unwashed } \\
\text { Electrolytic Film }\end{array}$ & $\begin{array}{c}\text { Washed } \\
\text { Electrolytic Films }\end{array}$ \\
\hline $35 \%$ & $7.8 \mathrm{~S} / \mathrm{cm}$ & $8.8 \mathrm{~S} / \mathrm{cm}$ \\
$40 \%$ & $8.5 \mathrm{~S} / \mathrm{cm}$ & $39.0 \mathrm{~S} / \mathrm{cm}$ \\
$45 \%$ & $11.1 \mathrm{~S} / \mathrm{cm}$ & $14.7 \mathrm{~S} / \mathrm{cm}$ \\
\hline
\end{tabular}



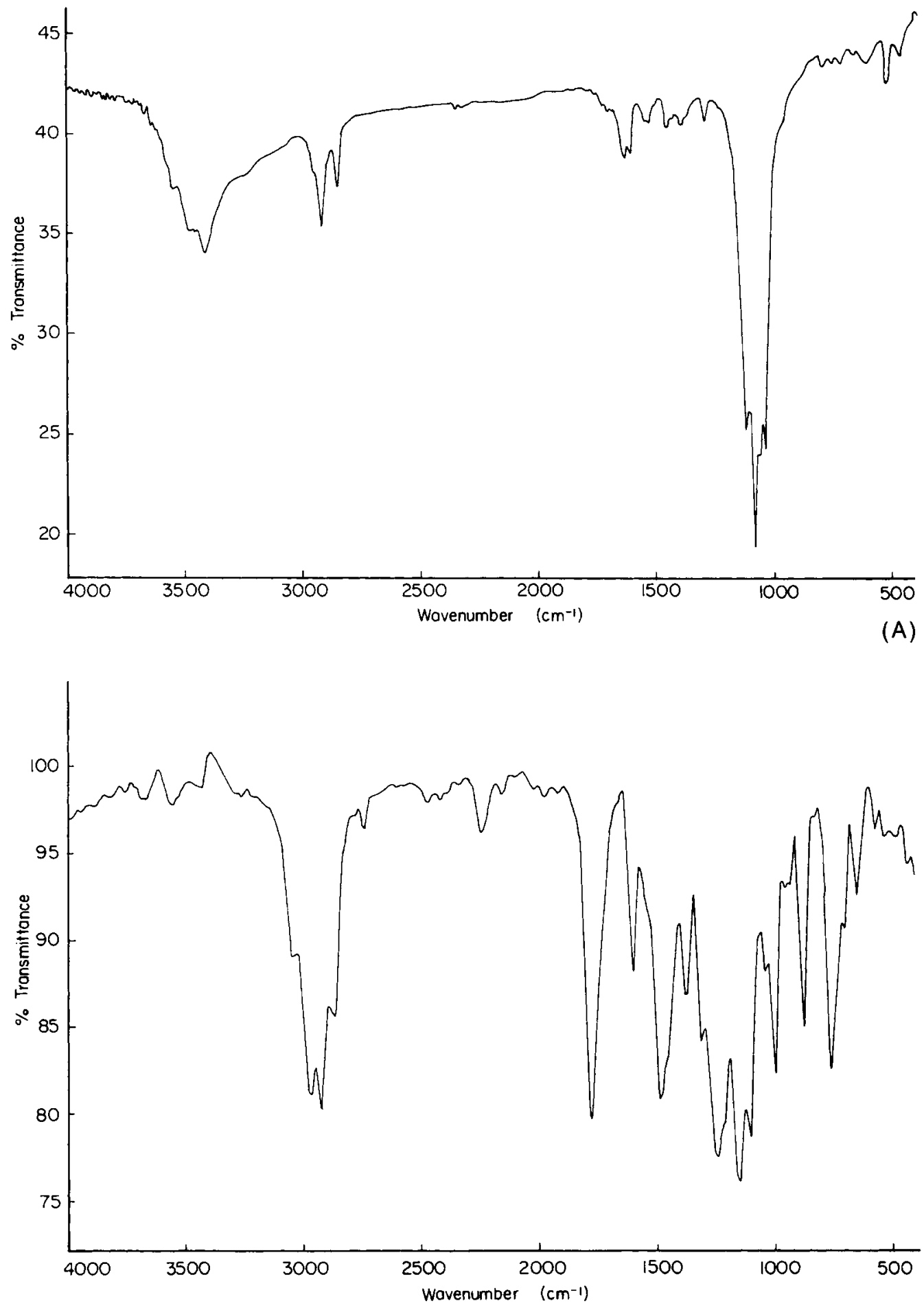

(B)

Figure 2 FTIR spectra: (A) PPy; (B) TMPC; (C) washed electrolytic film (50\% PPy wt/ wt); (D) unwashed electrolytic film (50\% PPy wt/wt). 

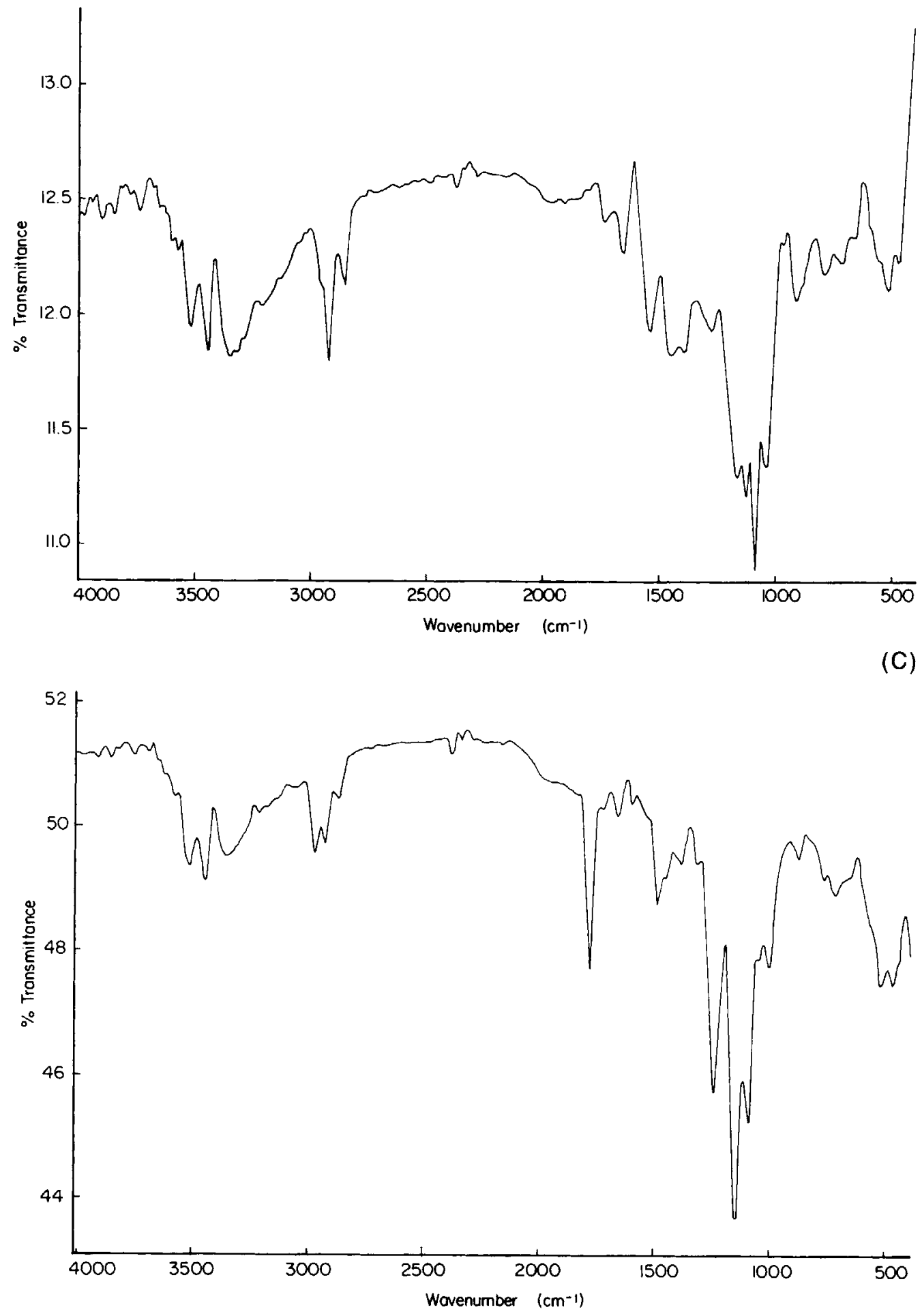

(D)

Figure 2 (Continued from the previous page) 

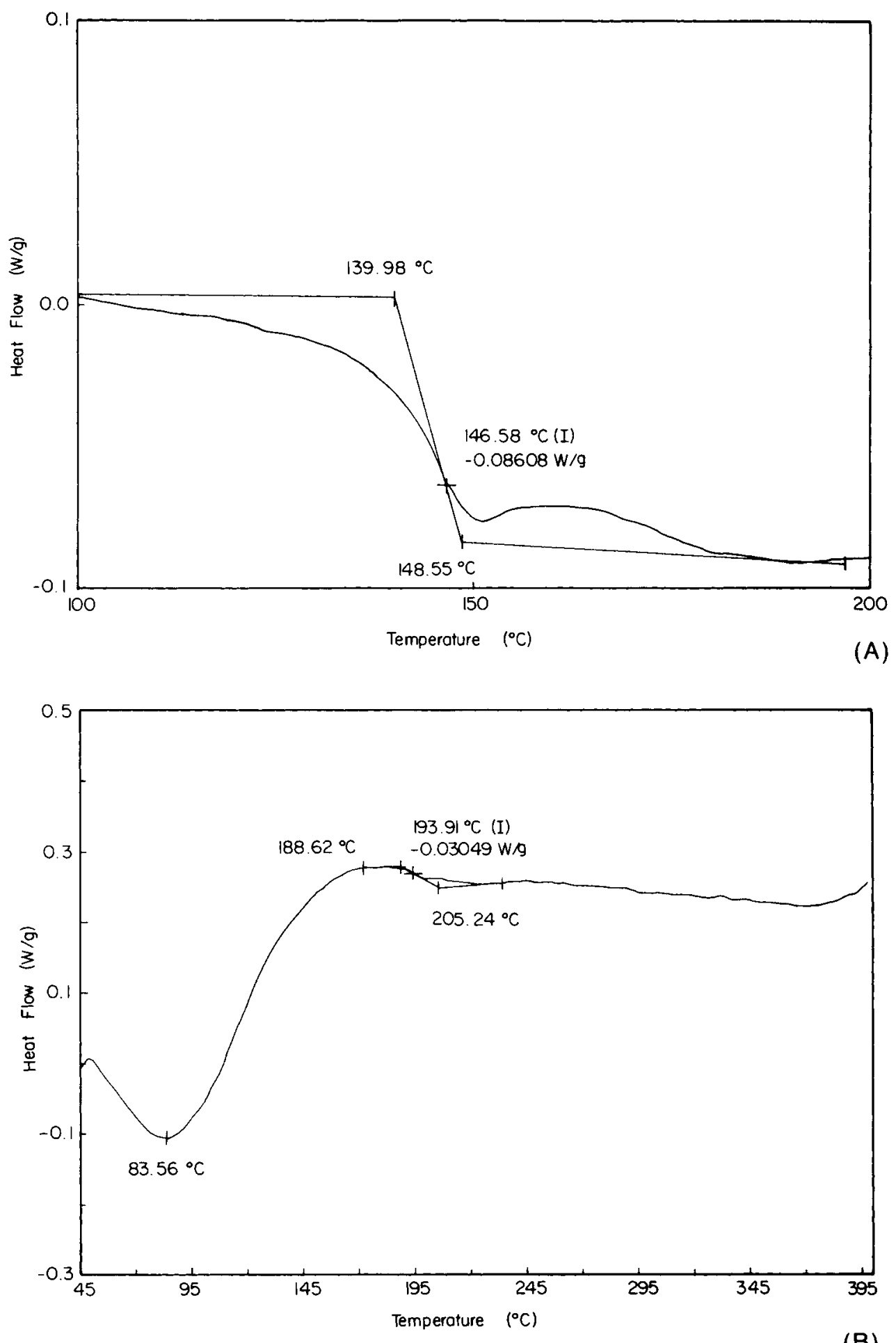

(B)

Figure 3 DSC results: (A) TMPC; (B) electrolytic film (40\% PPy wt/wt); (C) mechanical mixture of the two polymers $(40 \% \mathrm{PPy} w \mathrm{w} / \mathrm{wt})$. 


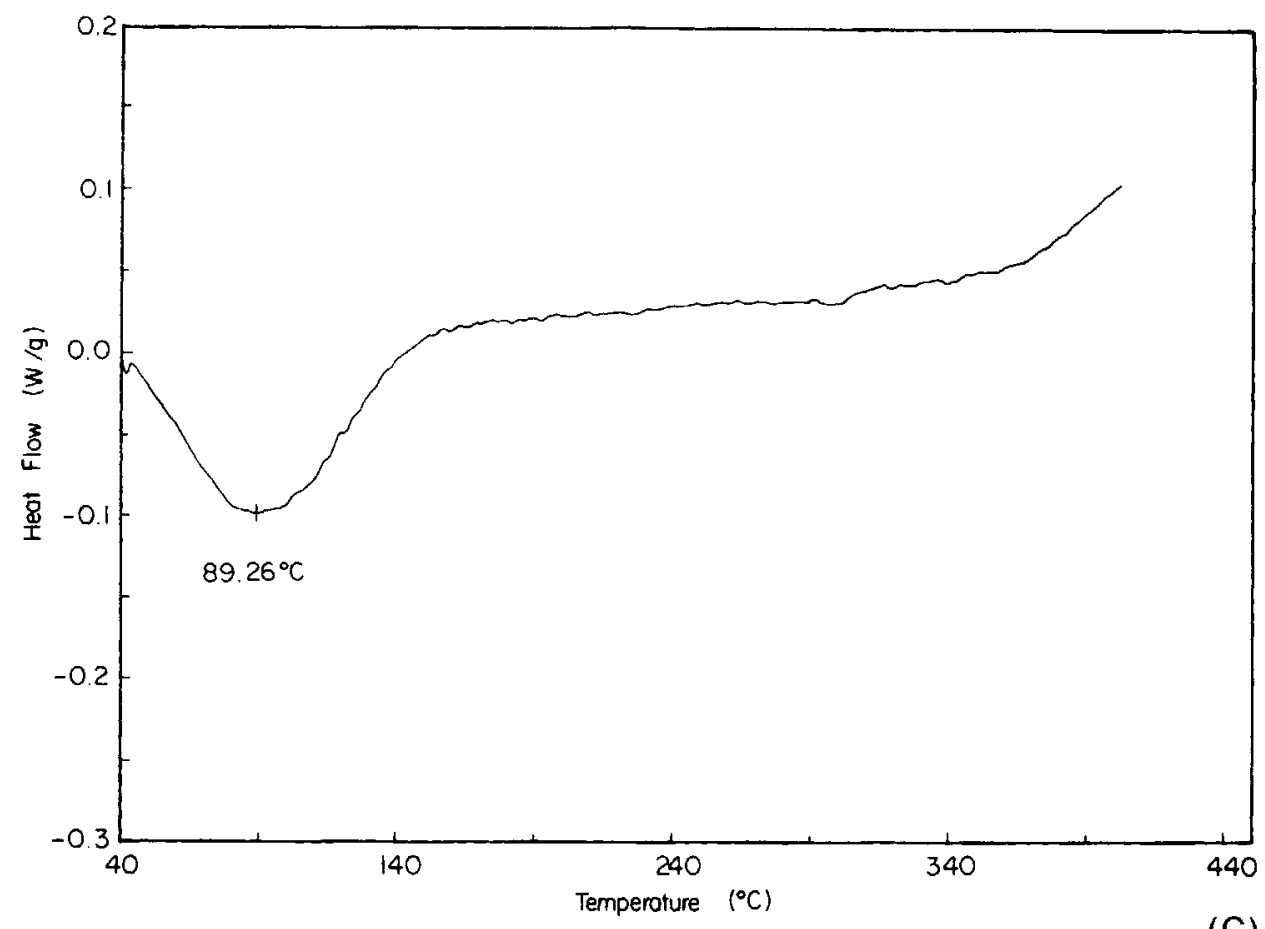

Figure 3 (Continued from the previous page)

(C)

Conductivities of the samples were measured via a four-probe technique. The composites were characterized by FTIR (Nicolet 510 FT-Spectrometer), SEM (JEOL JSM-6400 Scanning Microscope), DSC (910 S; Dupont Instrument), and TGA (951 Thermogravimetric Analyzer; Dupont Instrument).

\section{RESULTS AND DISCUSSION}

A black film was produced by electrochemical polymerization of pyrrole onto a TMPC-coated anode electrode. This film could readily be peeled off the electrode surface as a freestanding film.

Conductivities of several freestanding films in different PPy percentages were measured. As seen in Figure 1, which gives the relation between the composition and the conductivity of freestanding films, there is no percolation threshold; that is, conductivity increases correspondingly as the amount of conducting polymer increases in the composite.

The freestanding films were left in the chloroform, which is the solvent of the host polymer, for at least $1 \mathrm{wk}$. Weight loss revealed that TMPC, the host polymer, can be removed from the produced composite by simple washing. It was observed that after washing the freestanding films, the conductivity increased compared with unwashed films (Table
I). This may be attributed to the removing of the host polymer from the electrolytic film upon simple washing.

FTIR analysis of washed and unwashed freestanding films and pure conducting and insulating polymers was performed. Comparing the FTIR spectroscopies of washed and unwashed films indicated that the peak carbonyl moiety disappeared upon washing the film [Fig. $2(\mathrm{c}-\mathrm{d})$ ]. Moreover, no significant difference was observed between the FTIR spectra of the pure conducting polymer and the washed freestanding film [Fig. 2(a-c)]. These are evidence that the two polymers used in the synthesis of the composite forms only physical adhesion rather than chemical bonding.

DSC studies also revealed that thermal behavior of the PPy/TMPC electrolytic composite is not much different than that of a simple mechanical mixture of the two polymers (Fig. 3 ).

Interpretation of TGA scans is further evidence that PPy does not chemically interact with TMPC in the electrochemical preparation. The TGA scan of washed freestanding film is the same as the pure PPy film [Fig. 4(a-c)]. Examining the TGA of unwashed freestanding film revealed a weight loss corresponding to the loss of host polymer [Fig. 4(d)].

SEM studies revealed that the solution and electrode sides of the PPy/TMPC electrolytic composite 

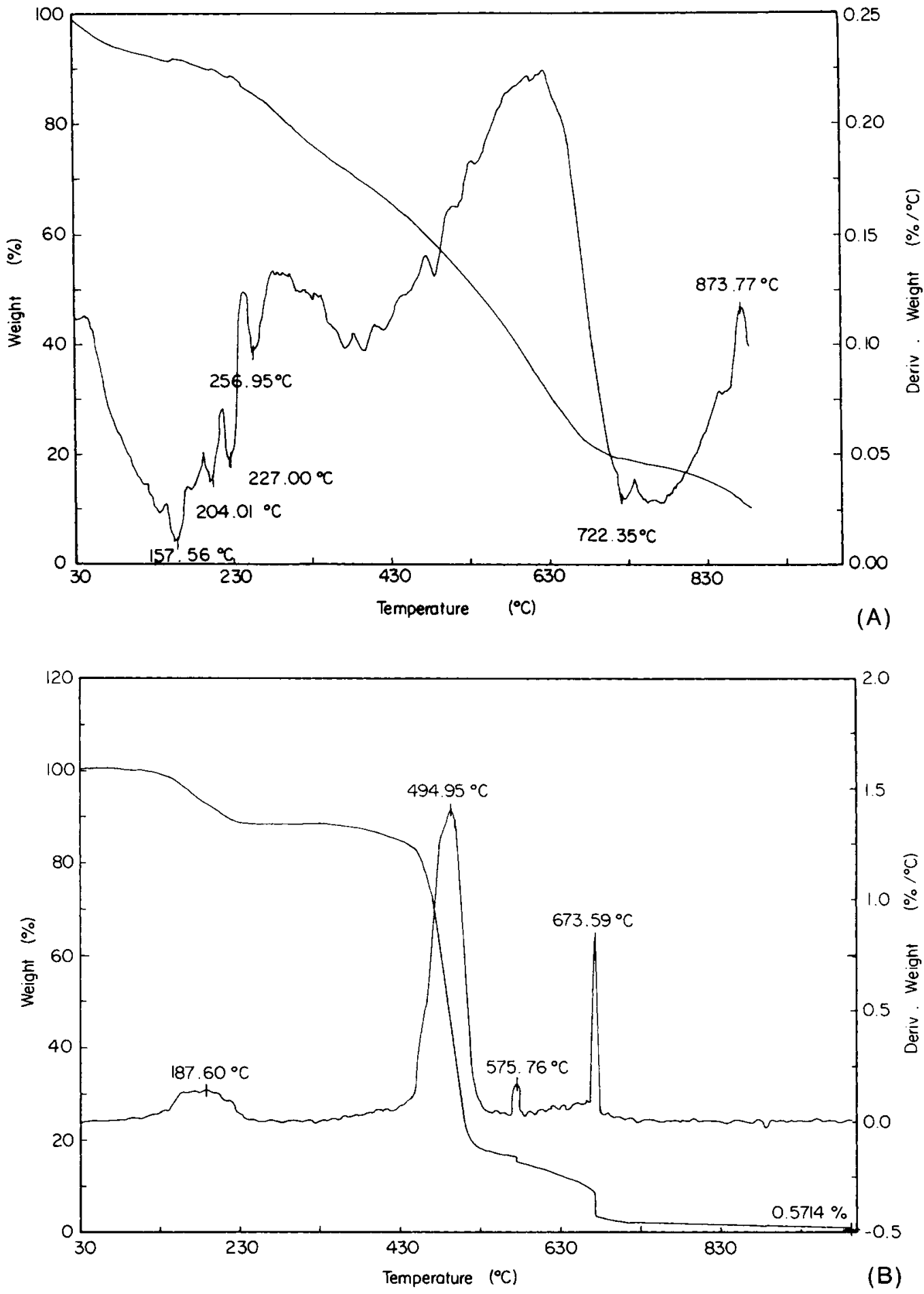

Figure 4 TGA: (A) PPy; (B) TMPC; (C) washed electrolytic film (40\% PPy wt/wt); (D) unwashed electrolytic film (40\% PPy wt/wt). 

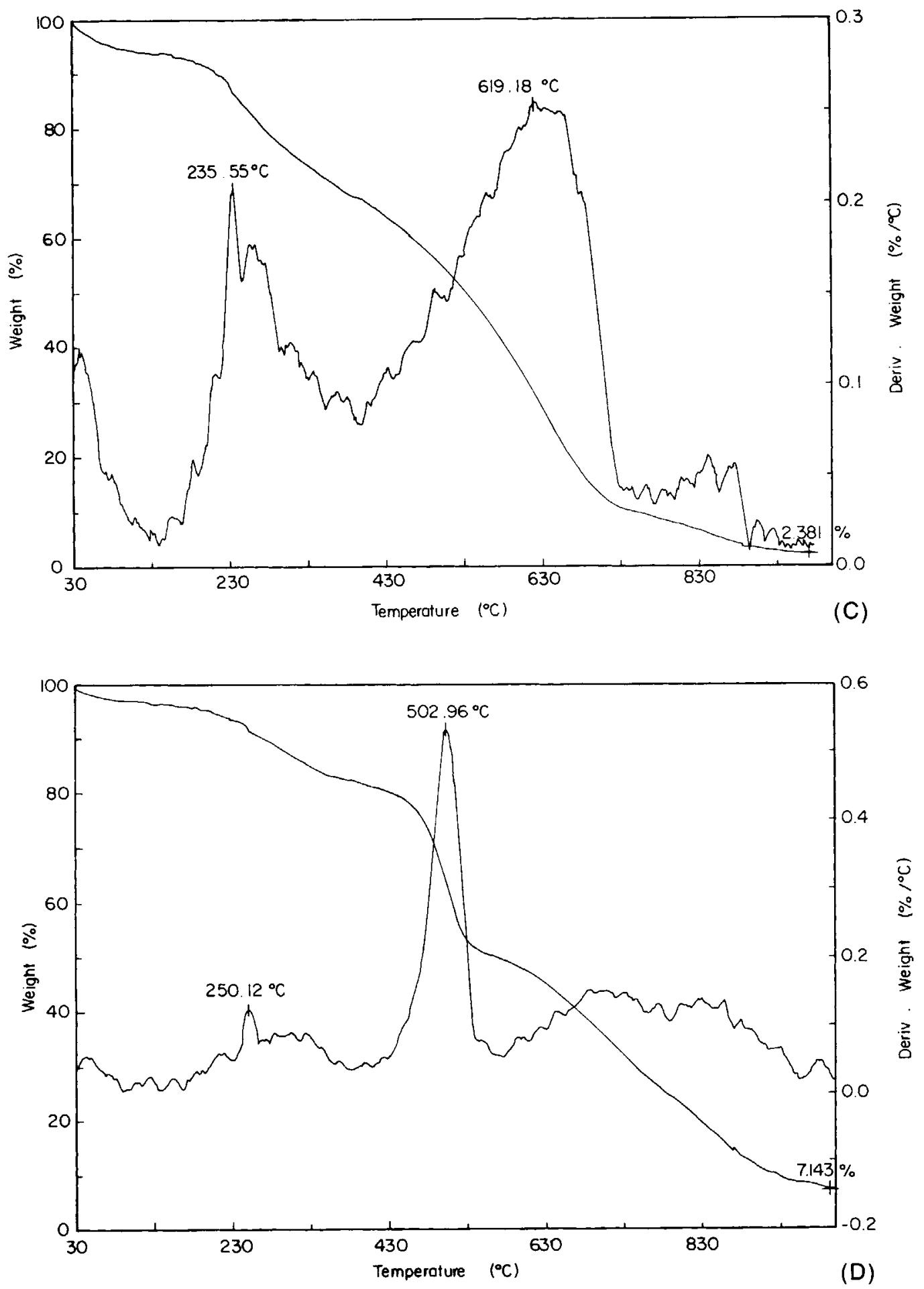

Figure 4 (Continued from the previous page) 

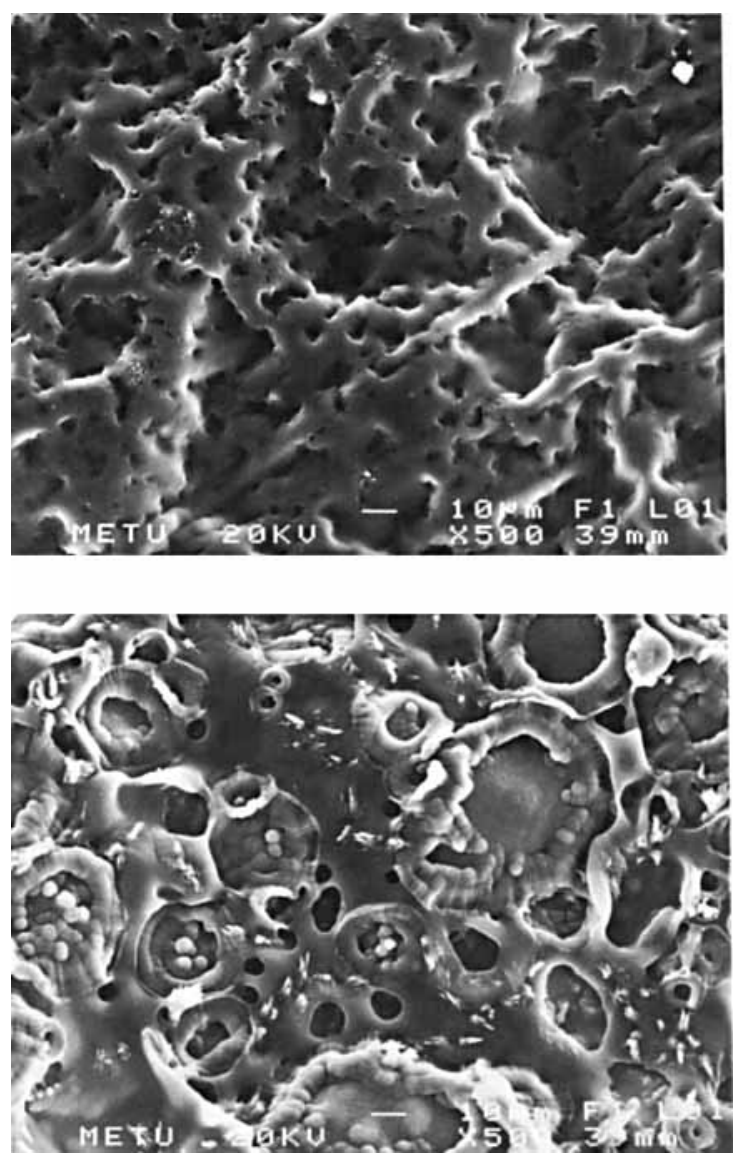

(b)

Figure 5 SEM micrographs of the electrolytic film: (A) electrode side; (B) solution side.

do not have the same morphology. The differing morphology of the two sides indicates that blending these two polymers electrochemically does form a composite rather than a graft copolymer ${ }^{15}$ (Fig. 5 ).

\section{CONCLUSION}

Evidence has indicated that PPy cannot be linked to TMPC in the PPy/TMPC composite as it can to polybisphenol-A carbonate. It may be strongly due to the steric hinderance of methyl groups attached to the phenyl groups, which prevents pyrrole oligomers from interacting with the carbonyl moiety of TMPC.

This study indirectly confirms the existence of $\mathrm{H}$-bonding between PPy and PC, and the formation of grafting in $\mathrm{PPy} / \mathrm{PC}$ composite.

\section{REFERENCES}

1. K. Kaneto, S. Ura, K. Yoshino, and Y. Inuishi, Jpn. J. Appl. Phys., 23, L189 (1984).

2. R. L. Elsenbaumer, K. Y. Jen, G. G. Miller, and L. W. Shacklette, Synth. Met., 118, 277 (1987).

3. G. Tourillon, in Handbook of Conducting Polymers, T. A. Skotheim., Ed., Marcel Dekker, New York, 1986.

4. D. Braun, D. Moses, C. Zhang, and A. J. Heeger, Synth. Met., 55, 4145 (1993).

5. S. Dogan, U. Akbulut, T. Yalçin, S. Süzer, and L. Toppare, Synth. Met., 60, 27 (1993).

6. A. F. Diaz, K. K. Kanazawa, and G. P. Gardini, J. Chem. Soc., Chem. Commun., 635 (1979).

7. G. Tourillon and F. Garnier, J. Electroanal. Chem., 135, 173 (1982).

8. A. F. Diaz and K. K. Kanazawa, Chem. Soc., 17, 45 (1981).

9. O. Niwa and T. Tamamura, J. Chem. Soc., Chem. Commun., 817 (1984).

10. M. De Paoli, R. J. Waltman, A. F. Diaz, and J. Bargon, J. Chem. Soc., Chem. Commun., 1015 (1984).

11. M.-A. De Paoli, R. J. Waltman, A. F. Diaz, and J. Bargon, J. Polym. Sci., Polym. Chem. Ed., 23, 1687 (1985).

12. O. Niwa, T. Tamamura, and M. Kakuchi, Macromolecules, 20, 749 ( 1987).

13. G. Nagasubramanian and S. DiStefano, J. Electrochem. Soc. Extended Abstr., 85, 659 (1985).

14. S. Doğan, U. Akbulut, and L. Toppare, Synth. Met., 53, 29 (1992)

15. F. Selampinar, U. Akbulut, T. Yalçin, Ş. Süzer, and L. Toppare, Synth. Met., 62, 201 (1994).

16. U. Geissler, M. L. Hallensleben, and L. Toppare, $A d v$. Mat., 104, 3 (1991).

17. U. Geissler, M. L. Hallensleben, and L. Toppare, Synth. Met., 40, 239 (1991).

18. R. Zallen, The Physics of Amorphous Solids, Wiley: New York, 1983, Chap. 4.

19. M. Aldiss and A. R. Bishop, Polymer, 26, 622 (1985).

20. S. Hotta, S. D. D. V. Rughooputh, and A. J. Heeger, Synth. Met., 221, 79 (1987).

21. H. L. Wang, L. Toppare, and J. E. Fernandez, Macromolecules, 23, 1053 (1990).

22. L. Toppare, S. Eren, Ö. Özel, and U. Akbulut, J. Macromol. Sci., Chem., 21, 1281 (1984).

Received May 15, 1995

Accepted December 26, 1995 